\title{
EFICIÊNCIA EM CAMPO DE DIFERENTES CONCENTRAÇÕES DE Condylorrhiza vestigiais multiple nucleopolyhedrovirus NO CONTROLE DE Condylorrhiza vestigiais
}

\author{
Edilene Buturi Machado ${ }^{1 *}$, Nilton José Sousa ${ }^{2}$, Flávio Moscardi ${ }^{3+}$ \\ ${ }^{1 *}$ Universidade Federal do Paraná, Programa de Pós Graduação em Ciências Florestais, Curitiba, Paraná, Brasil - \\ edilene.buturi.machado@gmail.com \\ ${ }^{2}$ Universidade Federal do Paraná, Departamento de Ciências Florestais, Curitiba, Paraná, Brasil - nilton.ufpr@gmail.com \\ ${ }_{3}^{3}$ Embrapa Soja, Londrina, Paraná, Brasil - In memoriam \\ Recebido para publicação: 23/06/2015 - Aceito para publicação: 02/03/2017
}

\begin{abstract}
Resumo
O gênero Populus é cultivado no Brasil nos estados do Paraná e Santa Catarina, a área plantada atualmente é cerca de 5.500 ha, a madeira produzida é destinada a produção de caixas e palitos de fósforo. A praga mais importante nestes plantios é a mariposa-do-álamo Condylorrhiza vestigialis (Guenée, 1854) (Lepidoptera: Crambidae). Entre as opções para o controle deste inseto, a mais promissora é um vírus de ocorrência natural do gênero Alphabaculovirus (NPV de Lepidoptera), espécie Condylorrhiza vestigialis multiple nucleopolyhedrovirus (CoveMNPV). Testes preliminares com este agente em laboratório indicam que o mesmo é eficiente para o controle de $C$. vestigiais. Porém não existem informações sobre a eficiência deste em condições de campo, fato que motivou a realização deste trabalho, visando os seguintes objetivos: a) avaliar em teste de campo, a eficiência de diferentes concentrações do vírus CoveMNPV em lagartas de C. vestigialis; b) comparar a eficiência de diferentes concentrações do vírus CoveMNPV, com a eficiência de um inseticida químico comercial (testemunha). Os resultados obtidos indicam que as concentrações virais $3 \times 10^{11} ; 6 \times 10^{11} \mathrm{e}$ $9 \times 10^{11}$ poliedros (OBs)/ha provocaram mortalidade de $67,1 \%, 68,3 \%$ e $93,4 \%$ respectivamente, para o inseticida químico, metoxifenozida, aplicado a $16,8 \mathrm{~g}$ i.a/ha constatou-se $87,9 \%$ de mortalidade. Com base nos resultados obtidos concluiu-se que: $\mathrm{O}$ maior percentual de mortalidade de lagartas de $C$. vestigialis é constatado na maior concentração do vírus CoveMNPV testada; a maior concentração do vírus CoveMNPV testada resultou em uma mortalidade de lagartas de $C$. vestigialis superior à provocada pelo produto químico metoxifenozida.

Palavras-chave: Mariposa-do-Álamo; vírus entomopatogênico; Populus; controle biológico.
\end{abstract}

\begin{abstract}
Field efficacy of different concentrations of Condylorrhiza vestigialis multiple nucleopolyhedrovirus for the control of Condylorrhiza vestigialis. The genus Populus is grown in Brazil in Paraná and Santa Catarina States, the commercial plantation currently is about 5,500 ha, the wood produced is intended for the production of boxes and matchsticks. The most important insect in these plantations is the Poplar moth Condylorrhiza vestigialis (Guenée, 1854) (Lepidoptera: Crambidae). Among the options for the control of this insect, the most promising is a naturally occurring virus of the genus Alphabaculovirus (Lepidoptera NPV), species Condylorrhiza vestigialis multiple nucleopolyhedrovirus (CoveMNPV). Preliminary tests with this agent in the laboratory indicate that it is effective for the control of C.vestigialis. However there is no information about the efficiency of this under field conditions, a fact that motivated this study, aimed at the following objectives: a) evaluate in field test, the efficiency of different concentrations of CoveMNPV virus in caterpillars of C.vestigialis; b) compare the effectiveness of different concentrations of CoveMNPV virus, with the efficiency of a commercial chemical insecticide (test). The results obtained indicate that viral concentrations $3 \times 10^{11} ; 6 \times 10^{11}$ and $9 \times 10^{11}$ Polyhedra (OBs)/ha provoked mortality of $67.1 \%, 68.3 \%$ and $93.4 \%$ respectively, for the chemical insecticide, methoxyfenozide, applied to $16.8 \mathrm{~g}$ i./ha caused $87.9 \%$ of mortality. Based on the results obtained it was concluded that: the highest percentage of mortality of caterpillars of $C$. vestigialis is found in higher concentration of the CoveMNPV virus tested; the highest concentration of CoveMNPV virus tested resulted in a higher mortality rate of C.vestigialis caterpillars than the chemical product methoxyfenozide.
\end{abstract}

Keywords: Poplar moth; entomopathogenic virus; Populus; biological control.

\section{INTRODUÇÃO}

O gênero Populus, popularmente chamado de Álamo ou Choupo pertence à família Salicaceae. É originário de regiões de clima temperado e frio do Hemisfério Norte, onde é amplamente cultivado, constituindo-se como uma das principais espécies de importância econômica (BALATINECZ et al, 2001; FAO, 2004). No Brasil 
este gênero é cultivado nos estados do Paraná e Santa Catarina, na Bacia do Rio Iguaçu, a área plantada atualmente é de cerca de 5.500 ha. A madeira destas plantações é destinada a produção de caixas e palitos de fósforo.

Dentre as pragas que atingem a referida cultura em plantios brasileiros, a mais importante é mariposado-álamo Condylorrhiza vestigiais (GUENÉE, 1854) (Lepidoptera: Crambidae). Essa praga vem merecendo destaque devido à sua alta capacidade reprodutiva, mas principalmente, em função dos prejuízos por ela causados, pois provoca desfolha intensa nas plantas, gerando danos no período de maior crescimento vegetativo das mesmas, entre dezembro e março.

Segundo Marques et al. (1995), as lagartas e C. vestigialis consomem todo o limbo da folha, permanecendo apenas as nervuras. De acordo com Diodato (1999), a desfolha ocorre em mais intensidade na parte superior da planta, os ataques ocorrem sempre em reboleiras e o nível de desfolha pode chegar a mais de $50 \%$ da área foliar das árvores. A mariposa-do-álamo reduz acentuadamente a sua população no outono e no inverno, neste período o inseto desaparece dos povoamentos, coincidindo com a fase em que a planta perde as folhas (DIODATO, 1999; SOUSA, 2002; MACHADO, 2006; CORRÊA, 2006; CORRÊA, 2008; CHIRINZANE, 2015), abrigando-se e sobrevivendo nas Salicaceas nativas que ocorrem nas matas ciliares próximas aos plantios (DIODATO; PEDROSA-MACEDO, 1996).

Para o controle deste inseto existe uma formulação de Bacillus thuringiensis, registrada para a cultura do Populus e uma formulação com a molécula química metoxifenozida em fase de registro. Além dos produtos citados, outras alternativas de controle já foram testadas, como formulações comerciais de fungos (Beauveria bassiana e Metharizium anisopliae), com resultados promissores em testes laboratoriais (SOUSA, 2002; DAL POGETTO; WILCKEN, 2012). Pesquisadores como Ambrogui et al. (2009) e Vidal (2012) têm desenvolvido testes promissores com feromônios sexuais de $C$. vestigialis.

Em relação à ocorrência de agentes naturais associados ao controle biológico de $C$. vestigialis, o agente mais promissor encontrado em campo é um vírus, que de acordo com Castro et al. (2003 e 2009) é um novo baculovirus do gênero Alphabaculovirus (NPV de Lepidoptera), espécie Condylorrhiza vestigialis multiple nucleopolyhedrovirus (CoveMNPV), que está classificado de acordo com a atual taxonomia da família Baculoviridae (HERNIOU et al., 2012). Entre outras vantagens, segundo Burges et al (1980), os vírus de poliedrose nuclear (VPN) não afetam o ser humano e não se desenvolvem em outros vertebrados, plantas, microorganismos e invertebrados não artrópodes.

Em experimentos realizados em laboratório Machado (2006) determinou que: a concentração letal (CL50) do vírus CoveMNPV para lagartas de C. vestigialis de $3^{\circ}$ instar é de $0,8 \times 10^{7} \mathrm{OB} / \mathrm{mL}$ de solução aquosa; o tempo letal (TL50) de ação foi de 7,48 dias; lagartas de terceiro ínstar de C.vestigialis infectadas por concentrações de $10^{7}$ e $10^{8} \mathrm{OBs} / \mathrm{mL}$ de suspensão aquosa, tem redução acentuada no consumo foliar, quando comparadas com lagartas sadias.

Em relação ao percentual de mortalidade provocado por diferentes concentrações de CoveMNPV, também em experimentos realizados em laboratório Machado (2006) constatou que a dose de $10^{8} \mathrm{OBs} / \mathrm{mL}$ é a mais apropriada para o controle de C. vestigialis, nove dias após a aplicação esta dose provocou $100 \%$ de mortalidade.

Obtidas essas informações preliminares sobre a eficiência do vírus citado em laboratório, surgiu a necessidade de avaliações sobre a eficiência desse agente em condições de campo, fato que motivou a realização desse trabalho, visando os seguintes objetivos: a) avaliar em teste de campo, a eficiência de diferentes concentrações do vírus CoveMNPV em lagartas de $C$. vestigialis; b) comparar a eficiência de diferentes concentrações do vírus CoveMNPV, com a eficiência de um inseticida químico comercial (testemunha).

\section{MATERIAL E MÉTODOS}

Os ensaios deste trabalho, foram conduzidos na Fazenda São Joaquim, localizada no município de São Mateus do Sul-PR, pertencente à Companhia Florestal Guapiara, em plantios do gênero Populus com dois anos de idade, plantados em espaçamento 6 × $6 \mathrm{~m}$, com altura média de $9 \mathrm{~m}$. Os talhões utilizados para instalação dos experimentos não haviam recebido nenhum tipo de controle durante o ciclo, apesar do ataque do inseto.

O CoveMNPV utilizado nos bioensaios foi obtido da coleção estoque de lagartas mortas pelo vírus citado do Laboratório de Proteção Florestal da UFPR. Essas lagartas são provenientes de populações naturais de C. vestigialis e foram coletadas de forma sistemática em locais isentos de pulverizações de inseticidas nas Fazendas São Joaquim (São Mateus do Sul, PR) e Pintado (Porto União, SC). As suspensões do vírus para cada tratamento foram preparadas a partir da retirada de alíquotas da solução-estoque, sendo que a determinação da concentração de corpos de oclusão $\mathrm{OBs} / \mathrm{mL}$ foi realizada previamente em laboratório, com o uso de câmara de Neubauer, de acordo com a metodologia indicada por Machado (2006).

A partir dessas determinações, com base nos experimentos de laboratório feitos por Machado (2006), que indicavam que a dose $10^{8} \mathrm{OBs} / \mathrm{mL}$ de Cove MNPV é a mais apropriada para o controle de C.vestigialis, 
obteve-se a dose de maior concentração, em seguida foram feitos os cálculos para a determinação das suspensões finais, que consistiram na diluição da dose inicial, originando as outras duas doses. Sendo assim, as alíquotas das suspensões estoque do vírus, destinadas a cada tratamento, foram preparadas para o transporte, sendo devidamente etiquetadas e acondicionadas em bolsas térmicas, com gelo, para evitar qualquer alteração do patógeno.

Foram utilizados cinco tratamentos, como seguem: três diferentes concentrações do vírus $\left(3 \times 10^{11}\right.$, $6 \times 10^{11}$ e $\left.9 \times 10^{11} \mathrm{OBs} / \mathrm{ha}\right)$; uma dose de $70 \mathrm{~mL}$ de p.c/ha base de Metoxifenozida (16,8 g de ingrediente ativo/ha), conforme recomendação de Sousa (2002); testemunha (pulverizada apenas com água).

Cada tratamento foi aplicado em três linhas de plantio contendo 20 plantas cada (60 plantas por tratamento e 300 plantas no total do experimento). Porém, para a amostragem, foram utilizadas apenas 10 árvores da fila central, totalizando 50 plantas avaliadas em todo o experimento. Entre cada tratamento foi deixada uma bordadura de cinco linhas, para evitar a deriva e a contaminação entre os tratamentos.

Definidos os tratamentos e as repetições, optou-se pela instalação do experimento em faixas, visto que para a utilização do delineamento de blocos ao acaso, que é indicado para experimentos de campo, seria necessária uma área muito extensa dificultando a instalação do experimento.

Antes da instalação do experimento, foi determinado o índice de infestação do inseto na área determinada para cada tratamento (faixa), através da retirada de um galho por árvore, sempre na mesma posição (terço médio da copa). Foram amostradas 10 árvores por tratamento, totalizando 50 árvores (galhos) amostradas em todo o experimento. Os galhos coletados foram etiquetados e acondicionados em sacos plásticos, sendo posteriormente levados à sede da Fazenda São Joaquim, onde foi determinado número total de lagartas de $C$. vestigialis por amostra.

As pulverizações foram realizadas com atomizador tipo canhão, acoplado a um trator, com vazão de 200L de calda/ha, no período das 16h:20 às 18h:40, com umidade relativa acima de 65\%. As pulverizações foram realizadas nesse período, pois, segundo Moscardi (1983), a radiação solar é o principal fator de desativação dos vírus pulverizados sobre folhas, e quando as soluções virais são aplicadas após às 16h, as soluções mantém o máximo da atividade original do vírus por $24 \mathrm{~h}$ após a aplicação.

Sete dias após a aplicação, foram realizadas novas coletas de amostras, seguindo os mesmos procedimentos realizados no levantamento preliminar. Os parâmetros analisados por amostra foram: número de lagartas sadias; número de lagartas com sintomas do vírus que segundo Moscardi (1983), Machado (2006) e Corrêa (2008) são a coloração amarelada no início da infecção, progredindo para coloração marrom escura, com redução da mobilidade e flacidez. Os sintomas resultantes do uso do produto químico Metoxifenozida, segundo Sousa (2002), são a coloração enegrecida do tegumento da larva, secreções anais e alterações da cápsula cefálica.

Os dados obtidos na pré-avaliação foram submetidos à análise de variância (ANOVA), para verificar se havia homogeneidade no número de lagartas entre as amostras avaliadas. Os dados oriundos da avaliação realizada sete dias após a aplicação dos tratamentos foram inicialmente submetidos a uma análise exploratória (teste de Shapiro-Wilk) e posteriormente a uma análise de variância (ANOVA) e teste de Tukey a 5\% de probabilidade.

\section{RESULTADOS E DISCUSSÃO}

Os resultados obtidos com a análise de variância dos dados referentes à avaliação preliminar indicaram homogeneidade da distribuição do número de lagartas na área analisada $(\mathrm{F}=0,2716$, p-valor $=0,8947)$. Os resultados obtidos pelo teste de Shapiro-Wilk ( $\mathrm{w}=0,96 \mathrm{e}$-valor $=0,12)$, referentes à análise exploratória dos dados coletados na avaliação realizada sete dias após as pulverizações, indicaram que os mesmos poderiam ser estudados, pois apresentaram distribuição normal.

Sete dias depois da instalação do experimento, 9,53\% das lagartas do tratamento testemunha estavam mortas, nestas observavam-se alterações morfológicas caracterizadas por tegumento amarelado ou escuro. Este percentual de mortalidade diferiu estatisticamente dos outros tratamentos (Tabela 1). Provavelmente este índice de mortalidade ocorreu pela ação de microrganismos dispersos naturalmente na área. Observação semelhante foi feita por Corrêa (2008), que também detectou mortalidade natural de lagartas de C. vestigialis durante experimentos que avaliaram a eficiência do CoveMNPV em pulverizações aéreas.

Para a concentração viral $\left(3 \times 10^{11} \mathrm{OB}\right.$ /ha do CoveMNPV), constatou-se uma mortalidade de $67,12 \%$, que não diferiu significativamente da segunda concentração $\left(6 \times 10^{11} \mathrm{OB} /\right.$ ha do CoveMNPV), que provocou $68,32 \%$ de mortalidade. Esses resultados, porém, diferiram significativamente da maior concentração $\left(9 \times 10^{11}\right.$ OBs/ha do CoveMNPV), que resultou em 93,43\% de mortalidade, que por sua vez igualou-se estatisticamente ao produto químico (metoxifenozida), que apresentou $87,91 \%$ de mortalidade, demonstrando a eficiência do vírus em condições de campo (Tabela 1).

FLORESTA, Curitiba, PR, v. 47, n. 2, p. 207 - 212, abr. / jun. 2017.

Machado, E. B. et al.

ISSN eletrônico 1982-4688

DOI: $10.5380 /$ rf.v47i1.41878 
Tabela 1. Porcentagem media de lagartas de C. vestigialis mortas por diferentes concentrações de CoveMNPV, comparadas com o inseticida Metoxifenozida (16,8 g i.a/ha), sete dias após a aplicação.

Table 1. Percentage average of $C$. vestigialis larvae killed by different concentrations of CoveMNPV, compared with the insecticide Methoxyfenozide ( $16.8 \mathrm{~g}$ i.a/ha), seven days after spraying.

\begin{tabular}{l|c}
\hline Tratamento & \% Média* \\
\hline Testemunha & $9,53 \mathrm{~A}$ \\
CoveMNPV - 3×1011 OBs/ha & $67,12 \mathrm{~B}$ \\
CoveMNPV - 6x10 11 OBs/ha & $68,32 \mathrm{~B}$ \\
CoveMNPV - 9x10 11 OBs/ha & $93,43 \mathrm{C}$ \\
Metoxifenozida- 16,8 g i.a/ha & $87,91 \mathrm{C}$ \\
\hline
\end{tabular}

* Médias seguidas da mesma letra não diferiram entre si, pelo teste de Tukey a 5\% de probabilidade.

Outro dado observado nesse bioensaio, diz respeito ao tamanho das lagartas e à ação do vírus. Embora não tenha sido realizada uma avaliação do tamanho das lagartas relacionando aos ínstares de C. vestigialis, as lagartas maiores eram as que ainda apresentavam movimentos aos sete dias após a aplicação, enquanto as menores já estavam mortas, ou seja, quanto mais jovem a lagarta, no momento da aplicação do vírus, mais rápida a ação do mesmo.

Isso indica que uma aplicação do vírus CoveMNPV quando as lagartas se encontram nos primeiros ínstares, mesmo em dose intermediária, pode resultar em controle eficiente da praga, desde que o monitoramento das áreas de Populus seja conduzido de forma contínua no período de ocorrência da lagarta. Esta constatação está de acordo com citações de Moscardi $(1999,2002)$ e Valicente et al (2009), que destacaram a importância de programar aplicações de vírus entomopatogênicos em ínstares iniciais de lepidópteros.

Outro fato constatado nos experimentos foi a persistência do vírus CoveMNPV em condições de campo, pela observação de lagartas recém eclodidas (primeiro e segundo ínstares) com sintomas da virose. Essa infecção pode ter ocorrido pela persistência do vírus nas folhas, ou ainda, por uma contaminação das folhas a partir de lagartas que morreram em um período menor de tempo e que tiveram seu tegumento rompido pela ação do vírus, liberando assim novas partículas virais.

De acordo com Moscardi (1998), em estudos realizados para a lagarta-da-soja, uma aplicação bem sucedida de baculovírus é suficiente para manter o controle durante o ciclo da cultura. $\mathrm{O}$ autor cita ainda que isso ocorre porque há uma reposição e redistribuição do vírus, devido aos focos deixados pelas lagartas mortas e pela grande quantidade de inóculos depositados no local de aplicação. Entretanto, para afirmar isso para o vírus CoveMNPV é preciso que sejam realizados ensaios de campo específicos que avaliem estes fatores.

Mesmo sem a confirmação citada, é importante ressaltar que a permanência e persistência do vírus no meio ambiente é uma das principais vantagens do inseticida biológico à base de vírus sobre a maioria dos inseticidas químicos, principalmente os de ação de contato que possuem um poder residual muito curto. Essa vantagem citada é descrita por Moscardi (1998), segundo o autor os vírus possuem a capacidade de se multiplicar no hospedeiro, permitindo sua persistência e disseminação no ambiente da praga, podendo mantê-la abaixo de níveis críticos para a cultura, após sua aplicação.

\section{CONCLUSÕES}

- O maior percentual de mortalidade de lagartas de C. vestigialis (93\%) é constatado na maior concentração do vírus CoveMNPV testada (9x10 $\left.0^{11} \mathrm{OBs} / \mathrm{ha}\right)$.

- A maior concentração do vírus CoveMNPV $\left(9 \times 10^{11} \mathrm{OB} / \mathrm{ha}\right)$ resultou em uma mortalidade de lagartas de $C$. vestigialis superior à provocada pelo produto químico Metoxifenozida, porém estatisticamente não foram observadas diferenças significativas entre os inseticidas biológico e químico.

\section{AGRADECIMENTOS}

Os autores agradecem pelo apoio acadêmico, administrativo, financeiro, técnico e logístico as seguintes instituições: UFPR, através do Programa de Pós-Graduação em Engenharia Florestal; FUPEF do Paraná; Empresa Swedish Match do Brasil; Companhia Florestal Guapiara. Também expressam agradecimentos à Dr ${ }^{\mathrm{a}}$ Maria Elita B. Castro da Embrapa Recursos Genéticos e Biotecnologia e ao Engenheiro Florestal MSc. Giancarlo Mira Otto.

\section{REFERÊNCIAS}

AMBROGUI, B. G.; FONSECA, M. G.; CORACINI, M. D. A.; ZARBIN, P. H. G. Calling behaviour and male response towards sex pheromone of poplar moth Condylorrhiza vestigialis (Lepidoptera: Crambidae). Journal of Pest Science, v. 82, n. 1, p. 55-60, 2009. 
BALATINECZ, J. J.; KRETSCHMANN, D. E. Properties and utilization of poplar wood. In: ICKMANN, D. I.; ISEBRANDS, J. G.; ECKENWALDER, J. E.; RICHARDSON, J. Poplar culture in North America. Ottawa, Canada. NRC Research Press, 2001. p. 277-291.

BURGES, H. D.; CROZIER, G.; HUBER, J. A review of safety tests on Baculoviruses. Entomophaga, Paris, v. 25, n. 4, p. 329-340, 1980.

CASTRO, M. E. B.; RIBEIRO, Z. M. A.; SOUZA, M. L.; SOUSA. N. J.; MOSCARDI, F. Identificação do baculovírus da lagarta-do-álamo Condylorrhiza vestigialis (Guenée, 1854) (Lepidoptera: Pyralidae). Embrapa Recursos Genéticos e Biotecnologia. Comunicado Técnico, 87 p. 2003.

CASTRO, M. E. B.; RIBEIRO, Z. M. A.; SANTOS, A. C. B.; SOUZA, M. L.; MACHADO, E. B.; SOUSA, N. J.; MOSCARDI, F. Identification of a new nucleopolyhedrovirus from naturally-infected Condylorrhiza vestigialis (Guenée) (Lepidoptera: Crambidae) larvae on poplar plantations in South Brazil. Journal of Invertebrate Pathology, v. 102, n. 2, p. 149-154, 2009.

CHIRINZANE, C. J. Criação de Condylorrhiza vestigialis (Guenée, 1854) (Lepidoptera: Crambidae), praga do gênero Populus, em laboratório usando diferentes dietas artificiais. Curitiba. Dissertação (Mestrado em Ciências Florestais) - Curso de Pós-Graduação em Engenharia Florestal do Setor de Ciências Agrárias da Universidade Federal do Paraná, 74 p, 2005.

CORRÊA, F. A. S. F. Criação em laboratório de Condylorrhiza vestigialis (Guenée, 1854) (Lepidoptera: Crambidae) com diferentes dietas artificiais. Curitiba. Dissertação (Mestrado em Ciências Florestais) - Curso de Pós-Graduação em Engenharia Florestal do Setor de Ciências Agrárias da Universidade Federal do Paraná, 2006.

CORRÊA, R. M. Classificação, determinação da eficiência, da compatibilidade e do comportamento em aplicação aérea do vírus Condylorrhiza vestigialis multiple nucleopolyhedrovirus. Curitiba. Tese (Doutorado em Ciências Florestais) - Curso de Pós-Graduação em Engenharia Florestal do Setor de Ciências Agrárias da Universidade Federal do Paraná, 2008.

DAL POGETTO, M. H. F. A.; WILCKEN, C. F. The effect of Beauveria bassiana on brazilian poplar moth Condylorrhiza vestigialis (Lepidoptera: Crambidae). Journal of Plant Protection Research. v. 52, n. 1, p. 1014, 2012.

DIODATO, M. A.; PEDROSA-MACEDO, J. H. Presencia de Condylorrhiza vestigialis (Guenée,1854) (Lepidoptera : Crambidae) sobre Populus spp. en el Brasil. Quebracho - Santiago del Estero, Argentina. n. 4, p. 17-19, 1996.

DIODATO, M. Bioecologia, aspectos morfológicos e consumo de Condylorrhiza vestigialis (Guenée, 1854) (Lepidoptera: Crambidae) em Populus deltoides Bart. Ex Marsh. (Salicaceae). Curitiba, 1999. Tese (Doutorado em Ciências) - Curso de Pós-Graduação em Entomologia do Setor de Ciências Biológicas da Universidade Federal do Paraná, 1999.

FAO. Sintesis de los informes nacionales de progreso recebidos, elaborados para a $22^{\mathrm{a}}$ Reunioón de La Comision Internacional del Álamo, organizada conjuntamente por la FAO y lãs Comisiones Nacionales del Álamo de Chile e Argentina; Santiago de Chile. 43 p. 2004.

HERNIOU, E. A.; ARIF, B. M.; BECNEL, J. J.; BLISSARD, G. W.; BONNING, B.; HARRISON, R.; JEHLE, J. A.; THEILMANN, D. A.; VLAK, J. M. Baculoviridae. In: King, A.M.Q., Adams, M.J., Carstens, E.B., Lefkowitz, E. J. Virus Taxonomy. Classification and Nomenclature of Viruses. Elsevier, Oxford, pp. 163174. 2012.

MARQUES, E. N.; SOUSA, N. J.; CORREA, R. de M.; GOMES, N. B. Ocorrência de Condylorrhyza vestigialis (Guenée, 1854) (Lepidoptera : Pyralidae) em povoamentos de Álamo Populus spp. No município de São Mateus do Sul - Paraná. Revista do Setor de Ciências Agrárias. Curitiba, v. 14. n. 1/2, p. 229-230, 1995.

MACHADO, E. B. Controle de Condylorrhiza vestigialis (Guenée,1854) (Lepidoptera: Crambidae), a mariposa do álamo, com uso do vírus Condylorrhiza vestigialis multiple nucleopolyhedrovirus (CvMNPV) em condições de laboratório e campo. Curitiba. Dissertação (Mestrado em Ciências Florestais) - Curso de PósGraduação em Engenharia Florestal do Setor de Ciências Agrárias da Universidade Federal do Paraná, 76 p, 2006.

MOSCARDI, F. Utilização de Baculovirus anticarsia para o controle da lagarta da soja Anticarsia gemmatalis. Comunicado Técnico 23. Embrapa - CNPSo, 1983.

MOSCARDI, F. Utilização de vírus entomopatogênico em campo. In: ALVES, S. B. Controle microbiano de

FLORESTA, Curitiba, PR, v. 47, n. 2, p. 207 - 212, abr. / jun. 2017.

Machado, E. B. et al.

ISSN eletrônico 1982-4688

DOI: $10.5380 /$ rf.v47i1.41878 
insetos. 2. ed. Piracicaba: Fealq, p. 509-539,1998.

MOSCARDI, F. Assessment of application of baculoviruses for control of Lepidoptera. Annual Review of Entomology 44, p. 257-289,1999.

MOSCARDI, F.; SOUZA, M. L. Baculovírus para o controle de pragas. Revista Biotecnologia Ciência \& Desenvolvimento, v. 24, p. 21-29, 2002.

SOUSA, N. J. Classificação de inseticidas e simulação de um programa de manejo de resistência para a mariposa-do-álamo (Condylorrhiza vestigialis (Guenée, 1854) - Lepidoptera: Crambidae). Curitiba. Tese (Doutorado em Ciências Florestais) - Programa de Pós-Graduação em Engenharia Florestal, do Setor de Ciências Agrárias da Universidade Federal do Paraná, 2002.

VAliCENTE, F. H.; TUELHER, E. S. Controle da lagarta-do-cartucho, Spodoptera frugiperda, com o Baculovirus spodoptera. Circular técnica 114 (Embrapa/Cnpms) - Sete Lagoas, MG,14p.,2009.

VIDAL, D. M. Identificação e síntese dos componentes do feromônio sexual de Condylorrhiza vestigialis (Lep.: Crambidae) e Edessa meditabunda (Hem.: Pentatomidae). Curitiba. Dissertação (Mestrado em Química) - Programa de Pós-Graduação em Química, do Setor de Ciências Exatas da Universidade Federal do Paraná, 2012. 